16. Сад и огород. Энциклопедический словарь. М.: Эксмо, Большая Российская энциклопедия, 2003. $864 \mathrm{c}$.

17. Яблоня (Malus) [Электронный ресурс] // Плантопедия. Садовые растения. - http://plantopedia.ru/ encyclopaedia/garden-plants/details/ya1/yablonya.

18. Алексеев Ю.Е., Жмылев П.Ю., Карпухина Е.А. Деревья и кустарники. Энциклопедия природы России. Справочное издание. М.: АBF, 1997. 592 с.
19. Игнатьева И.П. и др. Плодовые и овощные культуры СССР: Альбом. М.: Агропромиздат, 1990. $183 \mathrm{c}$.

20. Колесников Е.В. Яблоня и груша. М.: Россельхозиздат, $1985.56 \mathrm{c.}$

21. Государственный реестр селекционных достижений, допущенных к использованию. Т. 1. Сорта растений (официальное издание). М.: ФГБНУ Росинформагротех, 2018. 504 c.

\title{
CHARACTERISTICS OF THE WORLD AND RUSSIAN PRODUCTION OF FRUITS PRODUCTS (APPLES AND PEARS)
}

(C) 2018

\author{
Demenina Lyubov Georgievna, deputy director for science \\ Research Institute of Horticulture and Medicinal Plants «Zhiguliovskye Sady» (Samara, Russian Federation) \\ Petrova Anna Borisovna, postgraduate student of Ecology, Botany and Nature Protection Department \\ Savitskaya Kristina Andreevna, postgraduate student of Ecology, Botany and Nature Protection Department \\ Kavelenova Lyudmila Mikhailovna, doctor of biological sciences, \\ professor, head of Ecology, Botany and Nature Protection Department \\ Samara National Research University (Samara, Russian Federation)
}

Abstract. The paper deals with the peculiarities of the biological characteristics of the most important fruit crops of temperate climates - apple and pear (Rosaceae family, subfamily Maloideae), taking into account the world, national and regional cultivation. Both cultures are characterized by significant food and commodity value, have some differences in the chemical composition of the fruit, including the leading components of the mass and biologically active substances, which determine the peculiarities of their use in the human diet. In both global and national fruitgrowing, pears play a secondary role compared to apple, giving way to the number of varieties, the volume of production and the areas occupied. Based on the analysis of available statistical data of the FAO database, the dynamics of changes from 1990 to 2016 of the world production of apple and pear fruits with visualization on the continents, identifying world leaders and major trends are considered. For the USSR (from 1962 to 1990) and in Russian Federation (from 1992 to 2016) the paper presents a picture of changes in the volume of fruit production, discusses the status of fruit production in the country. The features of the historical development and current state of fruit growing in the Samara Region and prospects are discussed.

Keywords: Rosaceae family; fruit crops of temperate climates; representatives of the subfamily Maloideae; apple; pear; variety of sorts; cultivation in countries of the world; dynamics of changes; fruit production on continents; features of fruit production in the Russian Federation; prospects of industrial fruit growing in the Samara Region.

УДК 581.93

Статья поступила в редакцию 10.02.2018

\section{ФЛОРА СКВЕРА ИМ. К.В. ИВАНОВА ГОРОДА ЧЕБОКСАРЫ ЧУВАШСКОЙ РЕСПУБЛИКИ} (C) 2018

Димитриев Юрий Олегович, кандидат биологических наук, доцент кафедры биоэкологии и химии Чуваиский государственный педагогический университет им. И.Я. Яковлева (2. Чебоксары, Российская Федерация)

Аннотаиия. Сквер им. К.В. Иванова был заложен в 1930-е годы. Общая площадь 5,3 га. Преобладает Tilia cordata Mill. Флора сквера содержит 86 видов растений из 74 родов и 35 семейств. Хвойные представлены 2 видами - Larix sibirica Ledeb. и Picea pungens Engelm. К однодольным относится 6 видов из семейств Роасеае и Суреraceae. Систематическое разнообразие флоры очень низкое. Практически каждый род представлен лишь одним видом. Средний уровень видового богатства в одном семействе $-2,46$. Число семейств с одним видом - 19 (54,3\%). Десять ведущих по числу видов семейств концентрируют $64 \%$ видов. Спектр ведущих семейств флоры сквера указывает на её термофильный облик. Доля синантропных видов во флоре в целом - 61,6\%. Индекс синантропизации (Is) флоры сквера составляет 1,61 и подчёркивает антропогенный характер ландшафта. Аборигенная фракция флоры сильно изменена $(I s=0,61)$. В спектре жизненных форм преобладают гемикриптофиты $(33,7 \%)$, фанерофиты $(30,2 \%)$ и терофиты $(22,1 \%)$. Согласно системе биоморф И.Г. Серебрякова, доминируют многолетние травянистые растения (41,9\%), спектр которых отражает лесной тип биоценоза, однолетники (22,1\%), деревья $(19,8 \%)$ и кустарники $(10,5 \%)$. В эколого-ценотическом спектре преобладают сорные виды (36\%), лесные (18,6\%), виды культурценозов (17,4\%), луговые растения $(11,6 \%)$. В спектре гигроморф преобладают мезофиты $(72,1 \%)$, далее следуют ксеромезофиты $(15,1 \%)$, доля остальных групп колеблется от 1,2 до 5,8\%. В спектре трофоморф преобладают мезотрофы (57\%) и мегатрофы (37,2\%). Для сквера им. К.В. Иванова характерна стабильность функционирования, обеспечиваемая древеснокустарниковыми насаждениями. Газон сильно засорён и требует своей реконструкции.

Ключевые слова: флора; сквер; озеленение; Чебоксары; Чувашская Республика; экологическая оценка; таксономический анализ; синантропизация; жизненные формы растений; эколого-ценотический спектр; инвазионные растения; гигроморфы; трофоморфы. 


\section{Введение}

В публикации О.Б. Гонтарь и др., описывающей скверы города Мурманска, высказана хорошая мысль: «Каждый объект зелёного строительства города должен иметь подробное описание, включая особенности планировки, малых архитектурных форм (особенно исторических памятников), представителей флоры и фауны, а также архитектурных зданий, находящихся в непосредственной близости. Такие брошюры, при условии их регулярного переиздания, могут служить значительным подспорьем при мониторинге состояния растительности и исторических объектов» [1]. Однако, как правило, озеленённые городские территории имеют лишь паспорт объекта, содержащий сведения о дендрофлоре. Например, в Чебоксарах они были составлены в 2000-е годы специалистами МБУ «Управление экологии города Чебоксары». В этот же период флористическими исследованиями были охвачены некоторые парки и скверы Чебоксар: Центральный парк культуры и отдыха «Лакреевский лес» [2], парк культуры и отдыха им. 500-летия г. Чебоксары [3], лесопарк Гузовского [4], сквер им. 50-летия ВЛКСМ [5]. За последние годы были проведены эколого-флористические исследования сквера им. М. Горького [6; 7], Студенческого сквера [8; 9], сквера им. К.В. Иванова [10-12].

Последний заслуживает особого внимания по нескольким причинам. Во-первых, он является одним из старейших скверов в Чебоксарах, будучи заложенным ещё в 1930-е годы на месте разрушенного Никольского женского монастыря. Во-вторых, сквер является одним из рекреационно-туристских объектов г. Чебоксары: здесь установлен бронзовый бюст классика чувашской художественной литературы К.В. Иванова, автора поэмы «Нарспи», а также в ходе раскопок 2013 года была найдена предполагаемая усыпальница бабушки первого русского царя из рода Романовых Марии Шестовой и саркофаг с останками. В-третьих, сквер расположен в исторической части города на набережной Волги, откуда открывается прекрасный вид на Чебоксарское водохранилище, а потому является излюбленным местом летнего отдыха горожан и гостей столицы. Поэтому создание брошюры про сквер им. К.В. Иванова и включение информации о нём в туристские путеводители должны бы быть в сфере интересов администрации горо- да. Актуальность данной работы определяется ещё и тем, что осенью 2017 г. в рамках федерального проекта «Формирование комфортной городской среды» начались работы по благоустройству территории сквера, последний этап которых должен завершиться в 2018 г., и представленные флористические данные в последующем могут быть использованы для оценки произошедших изменений в растительном покрове сквера.

Целью настоящей статьи является комплексный анализ флоры сквера им. К.В. Иванова по состоянию на 2017 год и предложения по улучшению его экологического состояния.

\section{Объект, результаты исследования и их обсуждение}

Для более полного учёта растений использовался маршрутно-экскурсионный метод в сочетании с геоботаническим описанием пробных площадок и цветников. Виды определялись по «Флоре ...» П.Ф. Маевского [13].

Сквер им. К.В. Иванова расположен в Московском районе г. Чебоксары рядом со Свято-Троицким православным мужским монастырём. Сквер имеет прямоугольную форму с элементами регулярной планировки. Общая площадь - 5,3 га. Здесь произрастает около 150 деревьев, из которых половина приходится на липу мелколистную, определяющую общий облик сквера. Живая изгородь образована преимущественно Spiraea media Schmidt, реже Cotoneaster lucidus Schlecht., отдельные участки - Crataegus sanguinea Pall. и C. almaatensis Pojark., Rosa rugosa Thunb., Caragana arborescens Lam. [12].

Флора сквера им. К.В. Иванова насчитывает 86 видов сосудистых растений из 74 родов и 35 семейств (табл. 1). Хвойные представлены двумя видами: Larix sibirica Ledeb. и Picea pungens Engelm. Из 84 видов покрытосеменных растений к однодольным относится только 6 видов из семейств Роасеае и Cyperaceae: Bromopsis inermis (Leyss.) Holub, Dactylis glomerata L., Elytrigia repens (L.) Nevski, Poa compressa L., Carex appropinquata Schum. и Carex contigua Норре. Низкая доля однодольных растений, являющихся преимущественно влаголюбивыми видами, является косвенным свидетельством антропогенного влияния на растительный покров, включая рекреационную нагрузку.

таблица 1 - Основные параметры флоры сквера им. К.В. Иванова

\begin{tabular}{|c|c|c|c|c|c|c|c|c|c|c|}
\hline \multirow[b]{2}{*}{ Флора } & \multicolumn{3}{|c|}{ Число таксонов } & \multicolumn{3}{|c|}{ Пропорции флоры } & \multirow{2}{*}{$\begin{array}{c}\text { Доля } \\
\text { однодольных } \\
\text { среди } \\
\text { цветковых, } \\
\%\end{array}$} & \multirow{2}{*}{$\begin{array}{c}\text { Доля видов } \\
\text { в } 10 \text { ведущих } \\
\text { семействах, } \\
\%\end{array}$} & \multirow{2}{*}{$\begin{array}{c}\text { Соотноше- } \\
\text { ние } \\
\text { Asteraceae / } \\
\text { Poaceae }\end{array}$} & \multirow{2}{*}{$\begin{array}{l}\text { Индекс } \\
\text { синан- } \\
\text { тропиза- } \\
\text { ции Is }\end{array}$} \\
\hline & $\begin{array}{l}\text { Ви- } \\
\text { ды }\end{array}$ & $\begin{array}{l}\text { Po- } \\
\text { ды }\end{array}$ & $\begin{array}{l}\text { Се- } \\
\text { мей- } \\
\text { ства }\end{array}$ & $\mathrm{B} / \mathrm{C}$ & $\mathrm{B} / \mathrm{P}$ & $\mathrm{P} / \mathrm{C}$ & & & & \\
\hline Аборигенная & 53 & 47 & 25 & 2,12 & 1,13 & 1,88 & 11,3 & 66 & 2,25 & 0,61 \\
\hline Адвентивная & 33 & 31 & 17 & 1,94 & 1,06 & 1,82 & 0 & 78,8 & - & 1 \\
\hline В целом & 86 & 74 & 35 & 2,46 & 1,16 & 2,11 & 7,1 & 64 & 3,75 & 1,61 \\
\hline
\end{tabular}

Систематическое разнообразие флоры сквера очень низкое. Среднее число видов в семействе составляет 2,46. Лишь 8 семейств содержат 3 и более вида, насчитывая в общем 51 вид $(59,3 \%)$. Число семейств с одним видом - $19(54,3 \%): 11$ семейств из аборигенной фракции и 8 семейств из адвентивной
[10; 11]. Рассчитанные пропорции флоры демонстрируют обеднённость её состава.

«Свойственное каждой флоре распределение видов между систематическими категориями высшего ранга А.И. Толмачев (1974) назвал систематической структурой флоры» [14, с. 213]. В более узком смыс- 
ле можно говорить о флористическом спектре, отражающем состав и последовательность расположения семейств по числу видов. В сравнительных целях обычно используется не весь спектр, а лишь его головная часть, состоящая из 10-15 наиболее крупных («ведущих») семейств. Такой набор весьма четко характеризует принадлежность флоры к определенной флористической области [14] или экстремальные условия развития растительного мира [15].

Основу систематических спектров синантропизированных флор составляют 7-10 семейств, содержащих 60-69\% видов и более, что характерно для флор, развивающихся в условиях экстремальных сред [15], к каковым можно отнести урбанизированные территории. Высокий процент десяти ведущих семейств показатель большей трансформированности флор и соответственно меньшей их естественности. Во флоре сквера им. К.В. Иванова на 10 ведущих семейств приходится 64\%, что позволяет оценить флору сквера как естественную синантропизированную. Доля синантропных видов во флоре сквера составляет $61,6 \%$, причём из них на культивируемые интродуценты приходится $37,7 \%$. Если рассматривать индекс синантропизации Is (соотношение синантропных и несинантропных видов) [15], то видно, что территория сквера представляет собой антропогенный ландшафт $(I s=1,61)$, а аборигенная флора сильно изменена $(I s=0,61)$.
В спектре ведущих семейств флоры сквера им. К.В. Иванова (табл. 2) первые два места со значительным отрывом занимают Asteraceae (15 видов) и Rosaceae (13 видов). В спектре ведущих семейств Чувашии семейство Rosaceae находится на третьем месте после семейств Asteraceae и Роасеае, и его перемещение на второе место обусловлено наличием культивируемых интродуцентов из этого таксона (Cerasus vulgaris Mill., Cotoneaster lucidus Schlecht., Crataegus almaatensis Pojark., Crataegus sanguine Pall., Malus domestica Borkh., Padus maackii (Rupr.) Kom., Rosa rugosa Thunb., Spiraea media Schmidt).

Семейство Chenopodiaceae по числу видов выходит на третье место, что демонстрирует нарушенность травянистого покрова сквера, так как оно представлено сорными видами - Chenopodium album L., Ch. glaucum L., Ch. hybridum L., Ch. polyspermum L. и Atriplex patula L. Семейство Brassicaceae во флоpe сквера представлено исключительно синантропными адвентивными видами, являющимися сорными (за исключением Brassica oleracea L. var. acephala). Повышение роли семейств Chenopodiaceae, Brassicaceae, Fabaceae, Lamiaceae, Scrophulariaceae отражает термофильный характер флоры сквера. В результате происходит выпадение из флоры видов и родов, не адаптированных к условиям городской среды, что можно наблюдать на примере гигрофильного семейства Суреraceae, представленного в исследуемой флоре лишь двумя видами.

Таблица 2 - Ведущие семейства флоры сквера им. К.В. Иванова

\begin{tabular}{|l|c|c|c|c|c|c|c|c|c|}
\hline & \multicolumn{8}{|c|}{ Ранг ведущих семейств } \\
\cline { 2 - 8 } & 1 & 2 & 3 & 4 & 5 & 6 & 7 & 8 & 9 \\
\hline Флора в целом & $\mathrm{As}^{15}$ & $\mathrm{Ro}^{13}$ & $\mathrm{Ch}^{5}$ & \multicolumn{2}{|c|}{$\mathrm{Po}^{4}, \mathrm{Fa}^{4}, \mathrm{Br}^{4}$} & $\mathrm{Sc}^{3}, \mathrm{Ac}^{3}$ & $\mathrm{Lam}^{2}, \mathrm{Car}^{2}$ \\
\hline Аборигенная & $\mathrm{As}^{9}$ & $\mathrm{Ro}^{5}$ & \multicolumn{2}{|c|}{$\mathrm{Po}^{4}, \mathrm{Ch}^{4}$} & $\mathrm{Fa}^{3}$ & $\mathrm{Sc}^{2}, \mathrm{Ac}^{2}, \mathrm{Lam}^{2}, \mathrm{Car}^{2}, \mathrm{Plant}^{2}$ \\
\hline Адвентивная & $\mathrm{Ro}^{8}$ & $\mathrm{As}^{6}$ & $\mathrm{Br}^{4}$ & $\mathrm{Pin}^{2}$ & \multicolumn{4}{|c|}{$\mathrm{Fa}^{1}, \mathrm{Ch}^{1}, \mathrm{Am}^{1}, \mathrm{Ger}^{1}, \mathrm{Sc}^{1}, \mathrm{Ac}^{1}$} \\
\hline
\end{tabular}

Примечание. Ac-Aceraceae, Am-Amaranthaceae, $A s$ - Asteraceae, $\mathrm{Br}$ - Brassicaceae, Car - Caryophyllaceae, $\mathrm{Ch}$ - Chenopodiaceae, Fa - Fabaceae, Ger - Geraniaceae, Lam - Lamiaceae, Pin - Pinaceae, Plant - Plantaginaceae, $P o$ - Poaceae, Ro - Rosaceae, $S c$ - Scrophulariaceae. Число видов в семействе указано знаком степени.

Для эколого-флористической оценки территории часто используется спектр жизненных форм растений. По классификации биоморф К. Раункиера, во флоре сквера преобладают гемикриптофиты $(33,7 \%)$ за счёт аборигенных видов, фанерофиты $(30,2 \%)$ и терофиты $(22,1 \%)$ преимущественно за счёт адвентивных растений. Доля криптофитов $(7 \%)$ и хамефитов $(3,5 \%)$ невелика, что может быть связано с уплотнением субстрата [12]. Полученный спектр биоморф соответствует спектру, описанному М.А. Березуцким для антропогенно нарушенных территорий [16], и отражает искусственность ценоза, каковым является сквер. Согласно системе биоморф И.Г. Серебрякова, доминируют многолетние травянистые растения (41,9\%), спектр которых отражает лесной тип биоценоза, однолетники (22,1\%), деревья $(19,8 \%)$ и кустарники $(10,5 \%)$. Немалая доля однолетников (терофитов), представленных преимущественно сорными растениями, отражает умеренную антропогенную нагрузку на сквер [12].

В современных экологических исследованиях широко используется эколого-ценотический анализ флоры. В результате определения ценотической приуроченности видов растений был получен следующий спектр (табл. 3). С учетом ценотических особенностей урбанофлоры была выделена особая группа «виды культурценозов», включающая культивируемые интродуценты [17], так как «в некоторых формах городского зелёного покрова, например в парках... интродуценты играют важную роль в сложении растительного покрова и в выполнении им своих основных функций» [18].

Ведущим флороценотипом является сорный (31 вид), в котором преобладает рудеральный флороценоэлемент $(83,9 \%)$. Отдельно в травяном покрове доля сорных видов достигает 50\%, что является довольно высоким показателем и соответствует условиям произрастания на нестабильных, антропогенно нарушенных местообитаниях [10; 11]. Среди сорных видов стоит отметить злостные инвазионные виды, занесённые в «Чёрную книгу флоры Средней России» [19]: Acer negundo L., Conyza canadensis (L.) Cronq., Galinsoga ciliata (Rafin.) Blake, Lepidotheca suaveolens (Pursh) Nutt., Xanthoxalis stricta (L.) Small., 
a также опасный карантинный сорняк Cuscuta monogyna Vahl, паразитирующий на сирени обыкновенной.

Вторую позицию занимает лесной флороценотип, что соотносится с результатом анализа спектра жизненных форм травянистых многолетников, отражающим лесной тип биоценоза. Немногим меньше содержится видов культурценозов, что естественно для искусственных насаждений. На четвертом месте находится луговой флороценотип, что связано с наличием открытых пространств в центральной части сквера. Распределение остальных ценотических групп получается таким же, как у Студенческого сквера г. Чебоксары, и отражает черты бореальноумеренного типа флоры [9]. Представителем болотного флороценотипа является Carex appropinquata Schum., отмеченная у живой изгороди в нижней части сквера.

Таблица 3 - Эколого-ценотические группы растений во флоре сквера им. К.В. Иванова

\begin{tabular}{|c|l|c|}
\hline $\begin{array}{c}\text { № } \\
\text { п/п }\end{array}$ & \multicolumn{1}{|c|}{ Фитоценогруппы } & $\begin{array}{c}\text { Доля видов, } \\
\%\end{array}$ \\
\hline \multirow{2}{*}{1} & Сорные, & 36 \\
& в т.ч. рудеральные & 30,2 \\
\hline 2 & Лесные & 18,6 \\
\hline 3 & Виды культурценозов & 17,4 \\
\hline 4 & Луговые & 11,6 \\
\hline 5 & Лугово-лесные и опушечные & 8,1 \\
\hline 6 & Лесостепные & 2,3 \\
\hline 7 & Степные & 2,3 \\
\hline 8 & Прибрежно-водные & 2,3 \\
\hline 9 & Болотные & 1,2 \\
\hline
\end{tabular}

К наиболее существенным экологическим факторам, влияющим на структуру фитоценозов, относятся влажность почвы и богатство почвы питательными элементами. В соответствии с системой гигроморф и трофоморф А.Л. Бельгарда (в модификации Н.М. Матвеева [20]) были составлены соответствующие экологические спектры. В спектре гигроморф преобладают мезофиты $(72,1 \%)$, что свойственно флорам умеренной зоны и подтверждает бореальные черты исследуемой флоры. На втором месте находятся ксеромезофиты $(15,1 \%)$, что связано с уплотнённостью почвы, приводящей к некоторому дефициту влаги. Доля остальных групп колеблется от 1,2 до 5,8\%: гигромезофиты - 5,8\%, мезоксерофиты $3,5 \%$, ксерофиты - 2,3\%, гигрофиты - 1,2\%. Полученный спектр характеризует свежий гигротоп (свежий тип увлажнения почвы). В спектре трофоморф преобладают мезотрофы (57\%) и мегатрофы (37,2\%). Олиготрофы представлены четырьмя видами - Betula pendula Roth., Chamaenerion angustifolium (L.) Holub, Cuscuta monogyna Vahl, Oberna procumbens (Murr.) Ikonn. Галомегатрофом является Acer tataricum L. Таким образом, для сквера характерны среднеплодородные и плодородные почвы. Полученные спектры гигроморф и трофоморф практически совпадают с эдафотопическими структурами флор сквера им. М. Горького [6; 7] и Студенческого сквера г. Чебоксары [8; 9].
Вывод

Для сквера им. К.В. Иванова характерна стабильность функционирования, несмотря на его расположение вдоль относительно загруженной автотранспортным потоком улицы К. Иванова и наличие значительной рекреационной нагрузки. Стабильность обеспечивают древесно-кустарниковые насаждения, так как газон представлен сочетанием сорных видов растений с луговыми и требует своей реконструкции. Также необходима локализация и ликвидация очага заражения Cuscuta monogyna Vahl и замена отдельных участков сильно разреженной и утратившей декоративный вид живой изгороди. Полученные результаты могут быть использованы при реконструкции сквера им. К.В. Иванова, в фитомониторинге г. Чебоксары и обновлении паспорта сквера, составленного в 2005 г.

\section{Список литературы:}

1. Гонтарь О.Б., Макарова О.А., Дудакова Е.Ф. Скверы города Мурманска - экологические маршруты для изучения природы и истории родного края // Экологическое краеведение: мат-лы науч.-практич. конф. / отв. ред. О.С. Козловцева. Ишим: Изд-во ИПИ им. П.П. Ершова, 2016. С. 146-152.

2. Иванова С.В. Об итогах изучения флоры сосудистых растений «Центрального парка культуры и отдыха «Лакреевский лес» // Особо охраняемые территории в Приволжском федеральном округе. Научная, эколого-просветительская и охранная деятельность: мат-лы юбилейной конф., посвящ. 10-летию зап-ка «Присурский». Науч. тр. гос. природ. заповед. «Присурский». Чебоксары-Атрат, 2006. Т. 15. С. 7583.

3. Теплова Л.П., Бородина В.С. Парк культуры и отдыха им. 500-летия г. Чебоксары. Характеристика растительного покрова и флоры: Изучение биоразнообразия ООПТ в г. Чебоксары // Экол. вестн. Чуваш. Респ. Чебоксары, 2006. Вып. 53. Ч. 3. С. 6-12.

4. Гафурова М.М. Флористическое разнообразие и устойчивость городских дубрав правобережной части Чувашии // Устойчивость экосистем: теория и практика: мат-лы докл. всерос. науч. конф. с междунар. уч. 2010. Т. 1. С. 81-84.

5. Иванова С.В. Флора сосудистых растений «Сквера им. 50-летия ВЛКСМ» г. Чебоксары // Актуальные проблемы современного естествознания: матлы всерос. науч.-практ. конф. / под ред. Л.Н. Воронова, Н.В. Хураськиной, А.А. Шуканова. Чебоксары: Чувашгоспедун-т им. И.Я. Яковлева, 2006. С. 66-69.

6. Димитриев Ю.О., Гаврилова Т.В. Флора сквера им. М. Горького города Чебоксары Чувашской Республики // Научное обозрение. Биологические науки. 2017. № 1. C. 87-90.

7. Димитриев Ю.О., Гаврилова Т.В. Эдафотопическая структура флоры сквера им. М. Горького города Чебоксары Чувашской Республики // Биоэкологическое краеведение: мировые, российские и региональные проблемы: мат-лы 5-й междунар. науч.практ. конф., посв. 110-летию со дня рождения доктора биологических наук, профессора Л.В. Воржевой и 125-летию со дня рождения кандидата педагогических наук, доцента Г.Г. Штехера. 14 декабря 2016 г., г. Самара, Российская Федерация / отв. ред. С.И. Павлов. Самара: СГСПУ, 2016. С. 68-70. 
8. Димитриев Ю.О., Алексеева Е.П. Эколого-флористическая оценка сквера Студенческий города Чебоксары Чувашской Республики // Трешниковские чтения - 2017: Современная географическая картина мира и технологии географического образования: матлы всерос. науч.-практ. конф. / под ред. Н.А. Ильиной, Е.А. Артемьевой, В.Н. Федорова и др. Ульяновск: УлГПУ им. И.Н. Ульянова, 2017. С. 116-118.

9. Димитриев Ю.О. Флора Студенческого сквера города Чебоксары Чувашской Республики // Самарский научный вестник. 2017. Т. 6, № 4 (21). С. 35-41.

10. Димитриев Ю.О., Грошева Л.Г. О флоре сквера им. К.В. Иванова города Чебоксары Чувашской Республики // Любищевские чтения - 2017. Современные проблемы экологии и эволюции: сб. материалов всерос. (с междунар. уч.) науч. конф. (Ульяновск, 30-31 марта 2017 г.). Ульяновск: УлГПУ им. И.Н. Ульянова, 2017. С. 173-178.

11. Димитриев Ю.О., Грошева Л.Г. Флористическое обследование сквера им. К.В. Иванова города Чебоксары Чувашской Республики // Культура, наука, образование: проблемы и перспективы: мат-лы VI междунар. науч.-практ. конф. (г. Нижневартовск, 1315 февраля 2017 года). Нижневартовск: Изд-во Нижневарт. гос. ун-та, 2017. Ч. ІІ. Естественные и технические науки. С. 15-18.

12. Димитриев Ю.О. Биоморфологическая структура флоры сквера им. К.В. Иванова города Чебоксары Чувашской Республики // Биоэкологическое краеведение: мировые, российские и региональные проблемы: мат-лы 6-й междунар. науч.-практ. конф., посв. 105-летию со дня рождения доктора биологических наук, профессора В.Е. Тимофеева и 95-летию со дня рождения кандидата биологических наук, доцента А.И. Борисовой. 15 ноября 2017 г., г. Самара, Российская Федерация / отв. ред. С.И. Павлов. Самара: СГСПУ, 2017. С. 60-64.

\section{FLORA OF THE K.V. IVANOV SQUARE OF CHEBOKSARY OF CHUVASH REPUBLIC}

(C) 2018

Dimitriev Yury Olegovich, candidate of biological sciences,

associate professor of Bioecology and Chemistry Department

I. Yakovlev Chuvash State Pedagogical University (Cheboksary, Russian Federation)

Abstract. The square named after K.V. Ivanov was founded in the 1930s. The total area of 5,3 hectares. Tilia cordata Mill. Predominates. The flora of the square contains 86 plant species from 74 genera and 35 families. The division Pinophyta is represented by two species - Larix sibirica Ledeb. and Picea pungens Engelm. Six species from the families Poaceae and Cyperaceae are monocotyled. The systematic diversity of the flora is very low. Virtually every genus is represented by only one species. The average level of species wealth in one family is 2,46 . The number of families with one species is $19(54,3 \%)$. The top ten in the number of species families concentrate $64 \%$ of the species. The spectrum of the leading families of the square flora indicates its thermophilic appearance. The share of synanthropic species in the flora as a whole is $61,6 \%$. The index of synanthropization (Is) of the square flora is 1,61 and emphasizes the anthropogenic nature of the landscape. The aboriginal fraction of the flora is strongly altered ( $I s=0,61)$. In the spectrum of life forms hemicryptophytes $(33,7 \%)$, phanerophytes $(30,2 \%)$ and therophytes $(22,1 \%)$ dominate. According to the biomorphs system of I.G. Serebryakov perennial herbaceous plants $(41,9 \%)$ dominate, whose spectrum reflects the forest type of biocenosis, annuals $(22,1 \%)$, trees $(19,8 \%)$ and shrubs $(10,5 \%)$. In the ecologo-cenotic spectrum weed species $(36 \%)$, forest species $(18,6 \%)$, cultivar species $(17,4 \%)$, meadow plants $(11,6 \%)$ dominate. In the hygromorph spectrum mesophytes $(72,1 \%)$ dominate, then xeromesophytes $(15,1 \%)$ follow, the share of the remaining groups varies from 1,2 to $5,8 \%$. In the spectrum of trophomorphs mesotrophs (57\%) and megatrophs $(37,2 \%)$ dominate. The square named after K.V. Ivanov is characterized by stability of functioning, provided by wood and shrub plantations. The lawn is heavily clogged and requires its reconstruction.

Keywords: flora; square; gardening; Cheboksary; Chuvash Republic; environmental assessment; taxonomic analysis; synanthropization; plant life forms; ecologo-cenotic spectrum; invasive plants; hygromorphs; trophomorphs. 